\title{
Observed trends in indices for daily rainfall extremes specific to the agriculture sector in Lower Vellar River sub-basin, India
}

\section{Extreme rainfall trends over Lower Vellar sub-basin}

\author{
AmANDA JAYADAS* and N K AmbUJAm \\ Centre for Water Resources, Anna University, Chennai 600 025, India. \\ *Corresponding author.e-mail: amandaceg@yahoo.co.in, jayadasamanda@gmail.com
}

MS received 4 April 2017; revised 3 January 2018; accepted 1 June 2018; published online 1 March 2019

Globally, climate change has caused changes in frequency and intensity of climate extremes such as heat waves, droughts, floods and tropical cyclones. There is a need to understand the pattern of regional climate extremes to develop crucial adaptation strategies for the farming community. This paper focuses on developing the Expert Team on Climate Risk and Sector-specific Indices for rainfall, relevant for the agriculture and food security sector. The indices have been developed for Lower Vellar River subbasin, a coastal basin in Tamil Nadu, India. Trend analysis has been done for the climatic and cropping seasons in the sub-basin. Overall, there has not been any trend in the annual rainfall index values. The monthly trend values for the different indices have mostly exhibited insignificant trends throughout the study period (1978-2015) except for a few indices. Overall, the southwest monsoon season has shown a significantly decreasing trend in the indices. The northeast monsoon season has shown insignificant trends with positive slopes for most indices. There were insignificant or no trends in the indices for the summer season. The findings from the study can be used as a guiding tool for developing adaptation strategies, for the farming community.

Keywords. Climate variability and change; monsoon; observations; extreme climate indices; agriculture and food security; trend analysis.

\section{Introduction}

Climate change is a global phenomenon with long-term changes in surface air temperature and precipitation for at least a period of $30 \mathrm{yr}$. Global warming is a main driver for change in global atmospheric temperatures and related meteorological parameters. Global warming is attributed to anthropogenic activities which mainly include emission of greenhouse gases into the atmosphere. Burning of fossil fuels is a major contributor for increased atmospheric aerosol concentration
(Prasada Rao et al. 2010). Changes in frequency and intensity of climate extremes are due to such human influences on climate. Extreme weather events include unpredictable, severe or unseasonal events such as heat waves, droughts, floods and tropical cyclones. An extreme weather event becomes a disaster when the society or ecosystems are unable to cope with it effectively. It is difficult to determine the exact cause of an extreme event. The occurrence of extreme events such as heat waves has increased due to increased global warming, and the likelihood of other events such 
as frost or extremely cold nights, has decreased (Solomon et al. 2007). Changes in climate extremes can be studied both spatially and temporally. Rarer the extreme event, analysis becomes tedious since not many cases are available for consideration (Frei and Schär 2001; Klein Tank and Können 2003).

Since Indian economy is highly dependent on agriculture, much importance is given to any changes in rainfall. Agriculture is highly sensitive to climate and climate change. It may also be a driver for climate change. The impact of climate change on agriculture affects the food security of the growing population. The climate, cropping pattern, soil type, availability of resources and management practices vary from region to region. A comprehensive understanding of a region's climate is necessary for suggesting better adaptation strategies (Prasada Rao et al. 2010). Occurrence of climate extremes highly affects crop production leading to food insecurity, which in turn affects the country's economy. Food and non-food crop losses will increase with increase in weather-related disasters (Prasada Rao et al. 2010). As far as India is considered, there is an increased likelihood of wet summers, with greater flooding in the Asian monsoon region in a warmer climate (Palmer and Räisänen 2002). The increase in extreme events is very strong in many parts of India including the southern peninsular region (Sen Roy and Balling 2004). El Niño also has an effect on the monsoon in India resulting in heavy rainfall in the southern states of India, and it occurs once in 15-20 yr. This paper focuses on the assessment of climate extremes based on observational rainfall data. Trend analysis of extreme rainfall indices specific to the agricultural sector is carried out. Trends are calculated for the different climatic and local cropping seasons. Seasonal analysis has been conducted by averaging the monthly index values. The results of trend analysis have been verified with secondary data from previous studies.

The study is organised as follows. The description of the region of study is given in section 2. Data needed for the study, its processing and indices development, and trend analysis methodology are given in section 3. Section 4 highlights the results and discussion of the study followed by the conclusions in section 5 .

\section{Study area}

Details concerning the area of study have been collected from the Water Resources Department-
Public Works Department, Government of Tamil Nadu. Vellar River Basin is one of the 17 river basins in the state of Tamil Nadu in India. It is located between $11^{\circ} 10^{\prime} 56^{\prime \prime}-11^{\circ} 58^{\prime} 26^{\prime \prime} \mathrm{N}$ and $78^{\circ} 14^{\prime} 09^{\prime \prime}-79^{\circ} 48^{\prime} 53^{\prime \prime}$ E. It is bounded by Pennaiyar and Paravanar River Basins in the north, Cauvery River Basin in the west and south, and the Bay of Bengal in the east near Porto Novo. The basin has a total geographical area of $7504.35 \mathrm{~km}^{2}$, covering 22 taluks which include 40 blocks falling in parts of eight districts. The basin consists of seven sub-basins, namely Upper Vellar, Swethanadhi, Chinnar, Anaivari Odai, Gomukhinadhi, Manimukthanadhi and Lower Vellar. Physiographically, the Vellar Basin is divided into three divisions. They are (i) Western hilly terrain, (ii) Central hill valley complex terrain and (iii) Eastern deltaic plain and coastal region. Figure 1 shows the Vellar River Basin and its sub-basins.

Lower Vellar River sub-basin is located in the Eastern deltaic plain of Vellar Basin with the Bay of Bengal in the east. The sub-basin has a total geographical area of $1756.20 \mathrm{~km}^{2}$ covering 20 blocks in five districts namely Cuddalore, Villupuram, Ariyalur, Perambalur and Salem which are shown in figure 2. About $77.61 \%$ of the total geographical area of the sub-basin is covered by Cuddalore district which is the highest in the sub-basin. It has been observed that agriculture is one of the major activities of the people in the sub-basin. Around $28 \%$ of the sub-basin area is under irrigation, which is the highest among the entire basin. Paddy and sugarcane are the major crops in the sub-basin which are grown throughout the year. Paddy and sugarcane are both water-dependent crops thus making the farmers highly dependent on the monsoon.

Lower Vellar River sub-basin lies within the tropical monsoon zone and has tropical wet and dry/savannah climate. Based on the hydrometeorological features of the sub-basin, the year is divided into two periods: (i) monsoon period (June-December) and (ii) non-monsoon period (January-May). Rain during the monsoon season is due to the southwest (SW) trade winds which blow towards the Northern Hemisphere. The monsoon period is classified into SW monsoon period from June to September (4 months) and northeast (NE) monsoon period from October to December (3 months). During September the SW monsoon retreats followed by the onset of the NE monsoon. The NE monsoon is also known as the post-monsoon season or retreating $\mathrm{SW}$ monsoon 


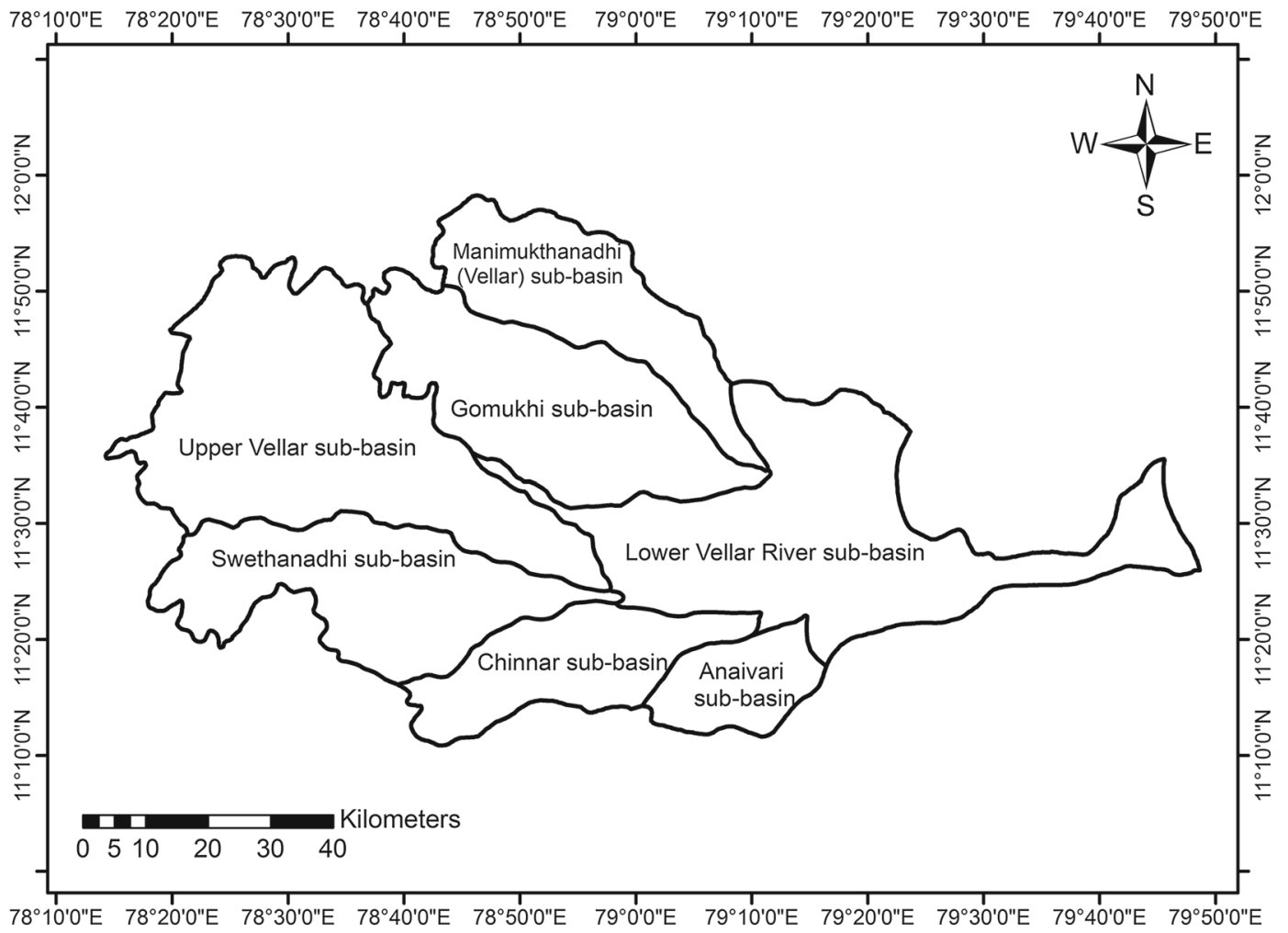

Figure 1. Location of Vellar River Basin and its sub-basins.

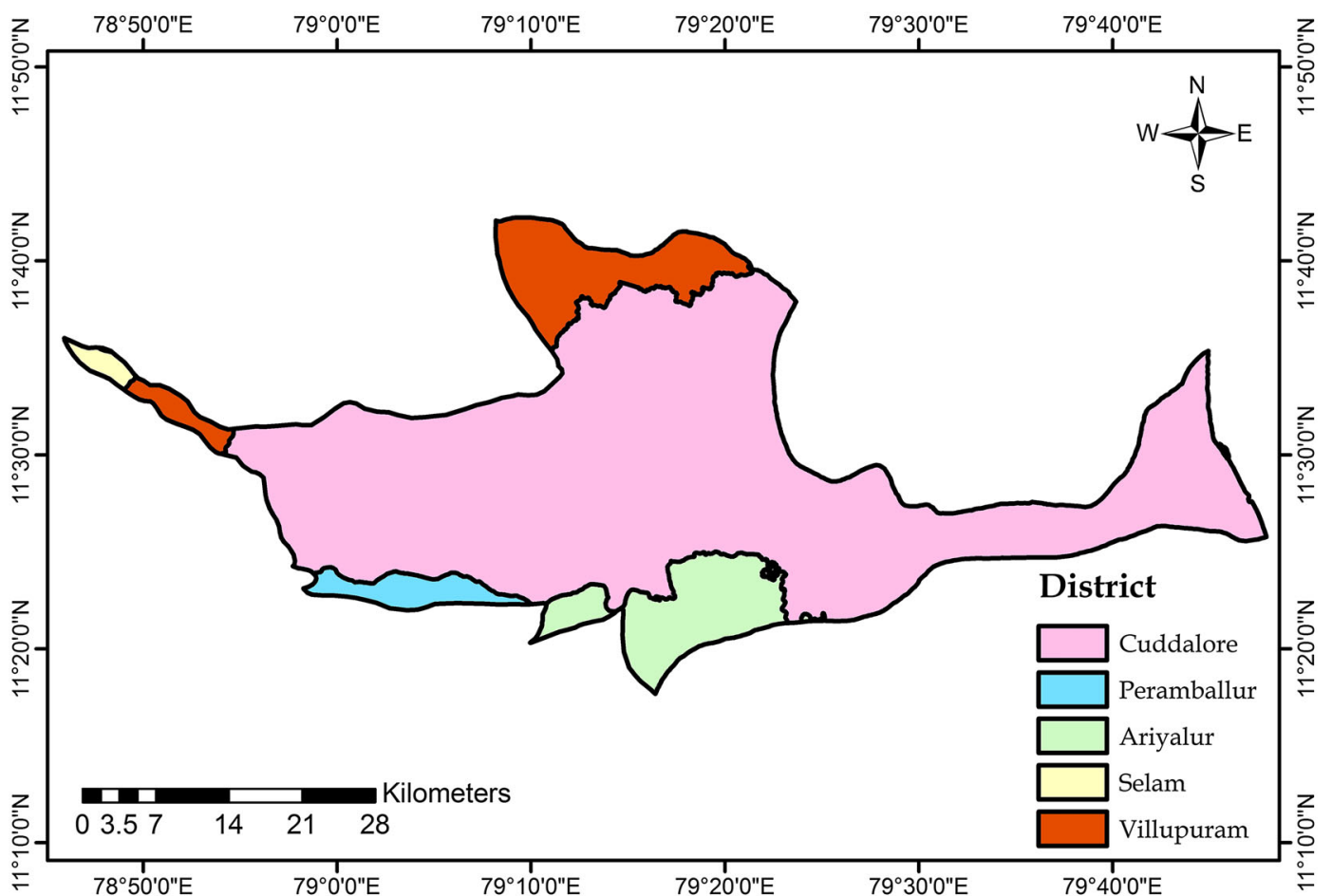

Figure 2. Districts falling within the Lower Vellar River sub-basin.

season. Retreat of SW monsoon is accompanied by rainfall from the tropical cyclones emerging in the neighbourhood of the Andaman Islands. During the month of December rainfall is from the dominant NE monsoon winds from the western disturbances emerging over the Mediterranean Sea. The NE monsoon supplies $60 \%$ of Tamil Nadu's annual water requirement and plays an important 
Table 1. Climatic and cropping seasons of Tamil Nadu.

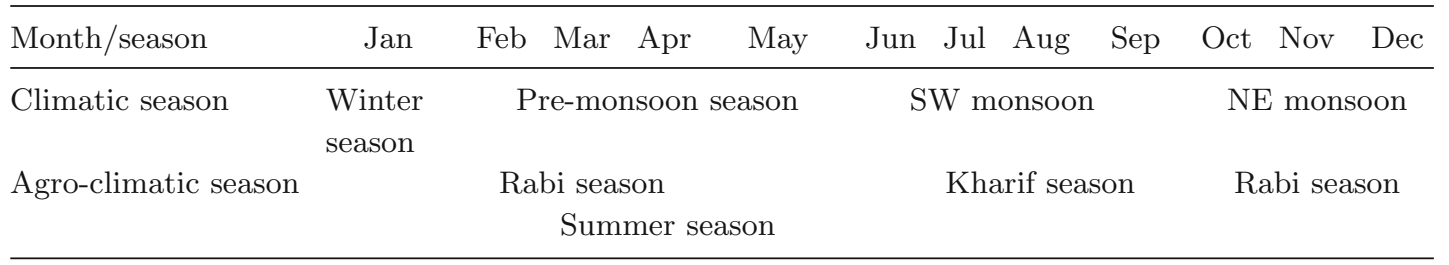

role in the agriculture and water resources sector of the state. Also, El Niño has a positive correlation with the NE monsoon, resulting in heavy rainfall in Tamil Nadu during extreme El Niño years (Geethalakshmi et al. 2009).

The non-monsoon period is sub-divided into winter period from January to February and premonsoon period from March to May. Rainfall in the winter season is due to the NE trade winds. The average annual rainfall for the sub-basin is $1176.6 \mathrm{~mm}$. The average rainfall during the NE monsoon season, SW monsoon season, winter season and pre-monsoon period are 654.6, 393.2, 32.6 and $96.2 \mathrm{~mm}$, respectively.

The agricultural cropping seasons are Kharif, Rabi and summer season. Kharif season is between June and October which falls within the SW monsoon season. Rabi season is between November and April/May. The summer season is for a short duration between March and June. The sub-basin is entirely dependent on rain for recharging its water sources and monsoon failure lead to acute water scarcity and severe drought. Table 1 shows the different climatic and cropping seasons of Tamil Nadu.

The cropping seasons are based on the monsoon, with rain fed crops planted during the NE monsoon season as Tamil Nadu gets the maximum rainfall during that season. The SW monsoon does not bring much rainfall since the sub-basin falls in the rain shadow region of the Western Ghats. During the SW monsoon season irrigated crops are grown.

\section{Data and methodology}

\subsection{Data source}

Daily rainfall data has been collected from Water Resources Department-Public Works Department, Government of Tamil Nadu. The list of influencing rain gauges within and nearby the sub-basin is given in table 2 along with the duration of data available. By visual analysis, missing data and its duration have been identified. Stations with missing data were not selected for the study. Based on the availability of data, the time period for the study has been fixed between 1978 and 2015 , so that a longer duration of observed data could be included in the analysis for better results. Figure 3 shows the location of the rain gauge stations selected for the study.

\subsection{ET-SCI indices}

Over the past few years, analysis of climate change and its impacts on various sectors have been done based on changes in the averages of climate data, either annually or seasonally. Analysis of climate extremes is the need of the hour since it has some major impact on different sectors such as agriculture, water resources, health and environment. The impacts include environmental, economic, social and socio-economic. Comprehensive analysis of climate extremes at a global level has been done previously by many researchers and academicians (Kiktev et al. 2003; Alexander et al. 2006). Not many studies have been carried out to highlight climate extremes at local levels. There is a necessity to carry out such studies at the regional level for the Indian sub-continent, since there have been many extreme rainfall events in the past two decades which has led to significant human and crop loss.

The joint Commission for Climatology $(\mathrm{CCl}) /$ World Climate Research Programme (WCRP)/ Joint Technical Commission for Oceanography and Marine Meteorology (JCOMM)/Expert Team on Climate Change Detection and Indices (ETCCDI) have developed a set of indices for detecting and identifying changes in climate extremes which include both temperature and precipitation. The indices have helped researchers to focus on measuring climatic variability and it has also been a guiding tool for recommending suitable measures to adapt to the changing climate. One main disadvantage of the ETCCDI indices was that the indices and their relevance for different sectors such as water resources, agriculture, health, etc., had not 


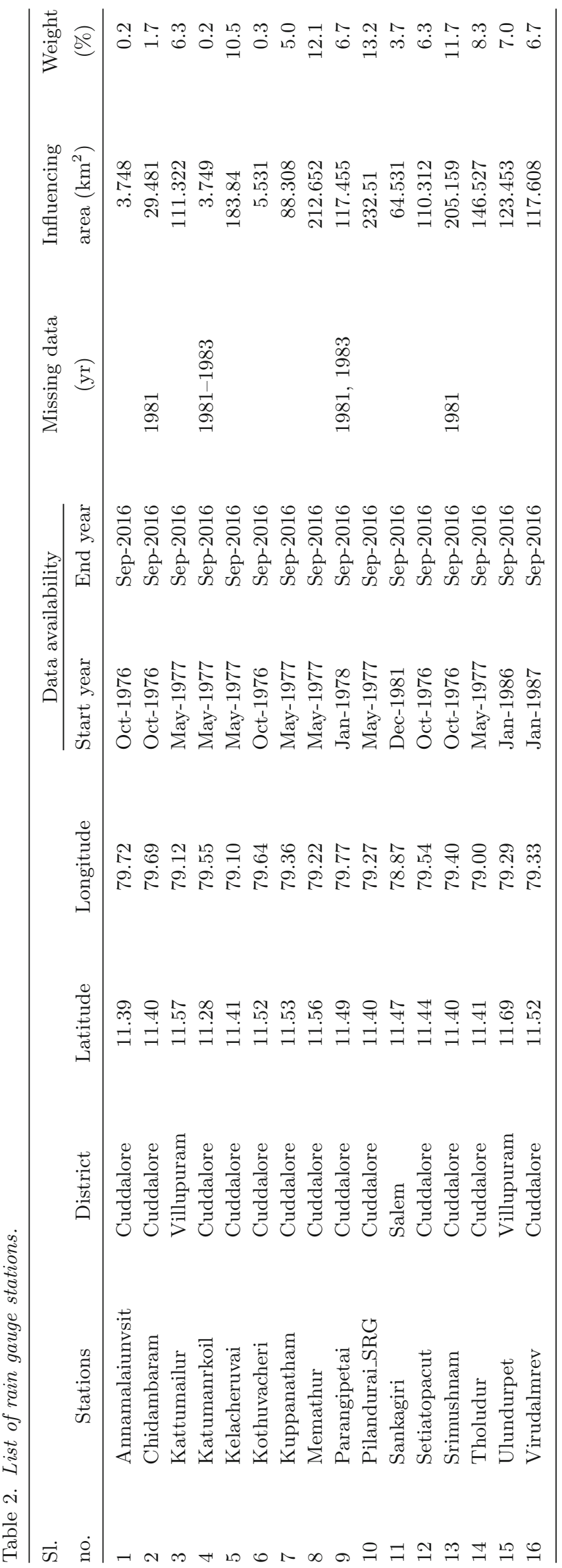

been identified. This led to the development of the Expert Team on Climate Risk and Sector-specific Indices (ET-CRSCI) which were more applicationrelevant and could be developed to better support adaptation. As a part of the development of the ET-CRSCI indices, the ClimPact software version 1.2 has been developed for data quality control and indices calculation. For homogeneity assessment no provision has been provided in ClimPact and hence researchers still use RHTest software.

The extreme precipitation indices considered for the study include percentile-based indices, absolute indices, threshold indices, duration indices and other indices. Percentile-based indices include very wet days (R95p) and extremely wet days (R99p). The precipitation indices in this category represent the amount of rainfall falling above the 95th (R95p) and 99th (R99p) percentiles. The percentile-based indices include and are not restricted to, the most extreme precipitation events in a year. Absolute indices represent maximum or minimum values within a season or a year. They include maximum 1-day precipitation amount (RX1day) and maximum 5-day precipitation amount (RX5day). Threshold indices are defined as the number of days on which a precipitation value falls above or below a fixed threshold, including number of heavy precipitation days $>10 \mathrm{~mm}$ (R10) and number of very heavy precipitation days $>30 \mathrm{~mm}$ (R30). These indices are not necessarily expressive for all climates because the fixed thresholds used in the definitions may not be applicable to different regions. Duration indices define periods of excessive wetness or dryness. They include consecutive dry days (CDD) and consecutive wet days (CWD). The CDD index is the length of the longest dry spell in a year while the CWD index is defined as the longest wet spell in a year. Other indices include indices of annual precipitation total (PRCPTOT), simple daily intensity index (SDII) and annual contribution from very wet days (R95pT) (Alexander et al. 2006). The details of the different indices are given in table 3 .

\subsection{Data quality control and homogeneity assessment}

Before the indices were calculated, the quality and homogeneity of the rainfall data was checked. Quality control of data includes identification of outliers and inhomogeneity. The presence of outliers in the data may be due to either genuine weather extremes or due to random recording errors. 


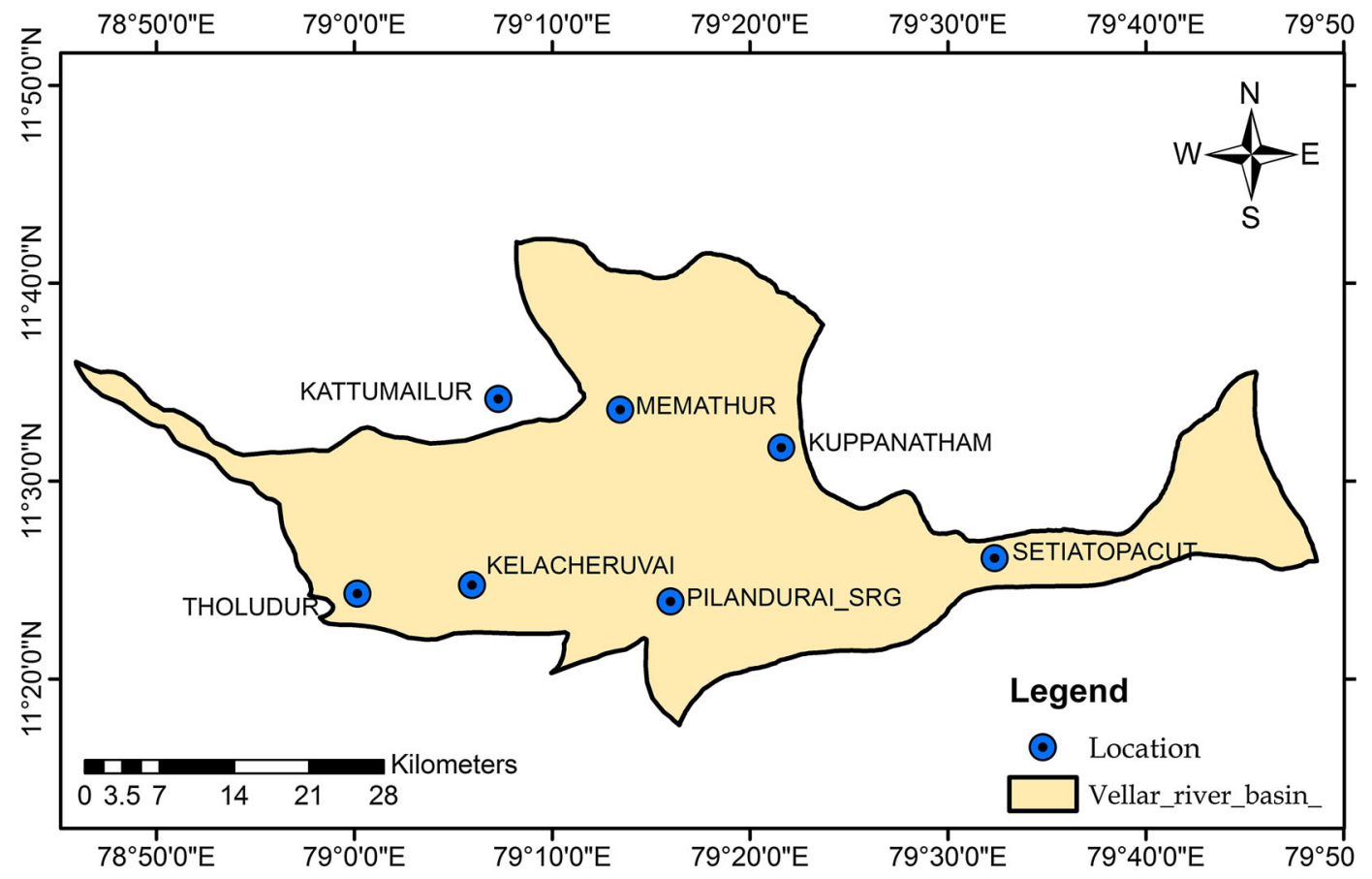

Figure 3. Spatial distribution of rain gauge stations selected for study in Lower Vellar River sub-basin.

Inhomogeneity or sudden step-change may be due to either genuine step-change in climate or due to changes in the way in which the data is recorded which include station location change or change in recording equipment. Generally, any such changes will be recorded and this 'metadata' will be maintained with the station records. With sufficient metadata available the discontinuity can potentially be corrected. If there is insufficient metadata, then it may be difficult to identify whether the step-change is a result of a real climatic shift or due to changed recording methods, and we may have to exclude the station from the analysis or consult with experts as to whether the data can be homogenised and used (McSweeney and Caesar 2013).

ClimPact software has been used for identification of outliers in the rainfall data. Since there is currently no provision for homogeneity assessment in ClimPact software, it has been done using RHtests_dlyPrcp software package which has been specifically designed for homogenisation of daily rainfall data time series (Wang et al. 2010; Wang and Feng 2013). Since metadata was unavailable for the rain gauge stations chosen for the analysis, the outliers were considered as missing data during homogeneity assessment. The software uses the penalised maximal $F$ test (PMF) for identifying and adjusting for any number of changepoints. No reference series is needed for identifying the changepoints in the rainfall series using the PMF method. Changepoints were identified for the dataset and documented. Since metadata was unavailable for the stations selected, based on advice from experts, homogeneity assessment was carried out for specific data sets. Significant changepoints were only considered and quantile matching method of adjusting the rainfall series was used for homogenising the data (Wang 2008a, b). The outliers that were considered as missing data during homogeneity assessment were included in the adjusted rainfall series for further analysis, thus preserving the rainfall extremes within the data. The results of quality control and homogenisation of the data are given in table 4 .

\subsection{Regional averaging of indices}

Since the indices were calculated at station level, a regionally averaged series was calculated for the indices data for all the rain gauge stations similar to the study of New et al. (2006). Standardisation was done for all the series such that it was not affected by stations having high or low indices values. The rainfall anomaly time series obtained from regional averaging has units in terms of standard deviation rather than the usual indices units. The anomaly series has been used for indices such as CDD, CWD, R10mm, R20mm, R30mm, R99pT, R95pT and SDII. For other indices data which have 


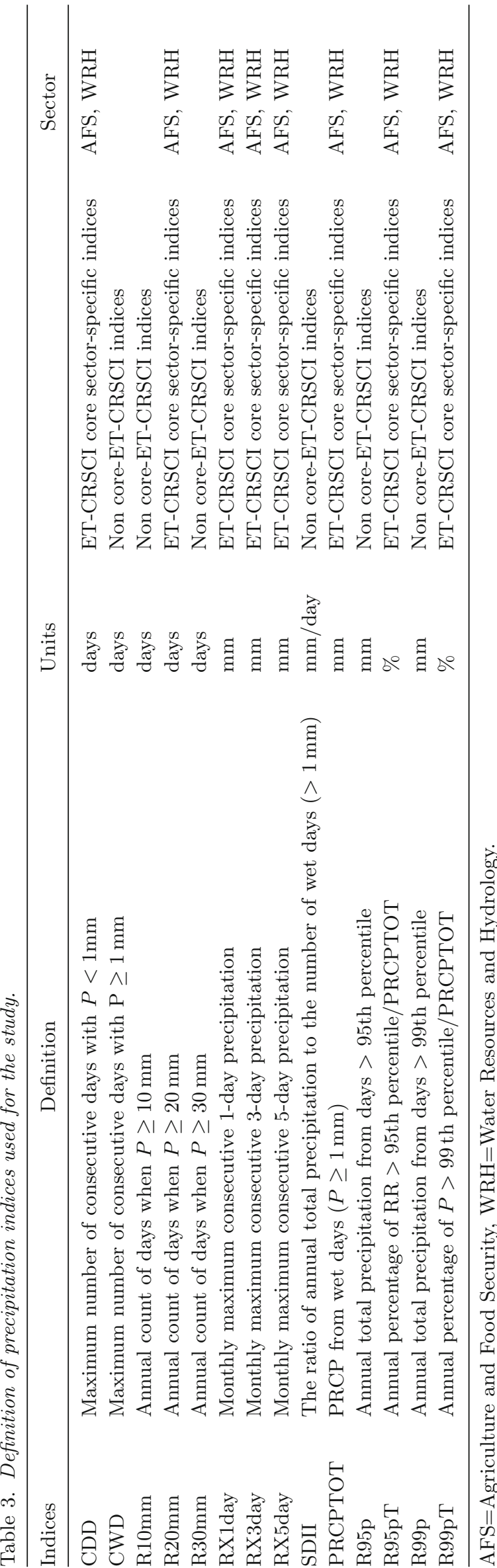

units in millimetres, such as R95p, R99p, PRCPTOT, Rx1day, Rx3day and Rx5day, the anomaly series was de-normalised to convert it into a series having units in millimetre (Jones and Hulme 1996).

\subsection{Trend analysis}

In general climate data does not have Gaussian distribution and has outliers, and hence a simple linear least squares method of estimating the trend will not be suitable. A robust method for identifying trends and slope of trends is necessary. Trends for the regionally averaged series were calculated using the Mann-Kendall's trend test (Mann 1945; Kendall 1955). The mathematical equations for calculating Mann-Kendall statistic $S$, variance $\sigma^{2}$ and standardised test statistic $Z$ are as follows:

$$
\begin{aligned}
& S=\sum_{i=1}^{n-1} \sum_{j=i+1}^{n} \operatorname{sgn}\left(X_{j}-X_{i}\right), \\
& \operatorname{sgn}\left(X_{j}-X_{i}\right)= \begin{cases}1 & \text { if }\left(X_{j}-X_{i}\right)>0, \\
0 & \text { if }\left(X_{j}-X_{i}\right)=0, \\
-1 & \text { if }\left(X_{j}-X_{i}\right)<0,\end{cases} \\
& \sigma^{2}=\frac{1}{18}[n(n-1)(2 n+5) \\
& Z= \begin{cases}\frac{S-1}{\sigma} & \text { if } S>0, \\
0 & \text { if } S=0, \\
\frac{S+1}{\sigma} & \text { if } S<0 .\end{cases}
\end{aligned}
$$

In the above equations $X_{i}$ and $X_{j}$ are the time series observations, $n$ is the length of time series, $t_{p}$ is the number of ties for $p$ th value and $q$ is the number of tied values. The test hypothesis for Mann-Kendall trend analysis is as follows:

Ho: There is no trend in the series.

Ha: There is a trend in the series.

Positive $Z$ values indicate an upward trend in the hydrologic time series and negative $Z$ values indicate a negative trend. The statistic $Z$ has a normal distribution. To test for either an upward or a downward monotone trend (a two-tailed test) at $\alpha$ level of significance, Ho was rejected if $|Z|>Z_{(1-\alpha / 2)}$, where $Z_{(1-\alpha / 2)}$ was obtained from the standard normal cumulative distribution tables. The $Z$ values were tested at $10 \%$ level of significance. 


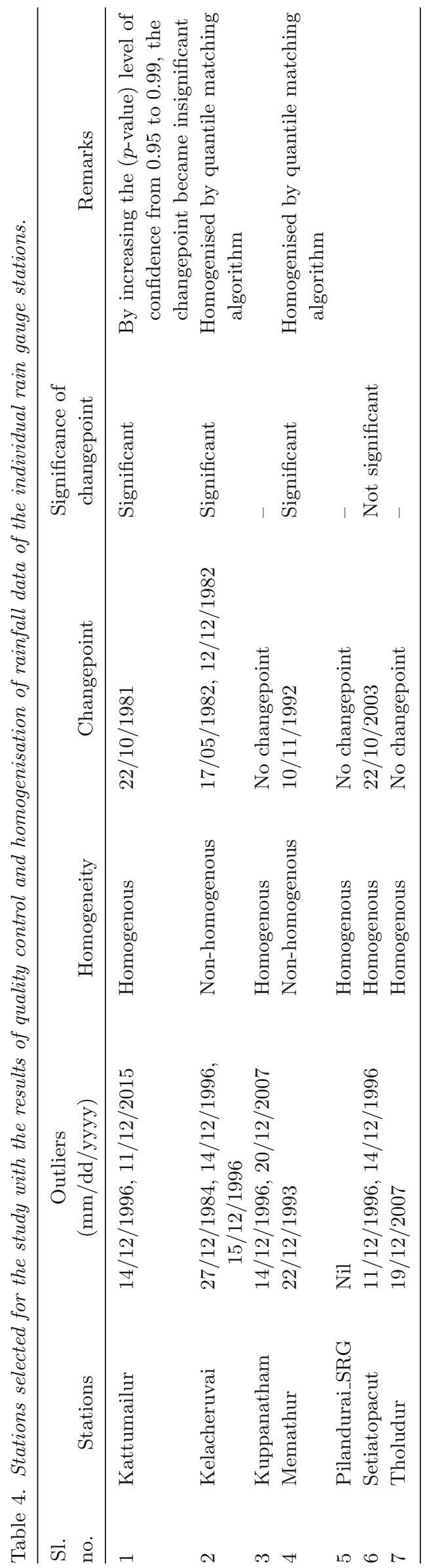

The trend slope was estimated following an approach by Sen (1968). Sen's slope estimator is insensitive to outliers and is the most popular nonparametric technique for estimating a linear trend. The significance of the trend has been assessed using the Kendall's test since it does not assume a distribution for the residuals and is robust to the effect of outliers in the series (Alexander et al. 2006). The Sen's slope estimate is the median of the slopes calculated from all joining pairs of points in the series and the confidence interval is obtained from the tabulated values of Kendall (1955). Autocorrelation in the indices data is the presence of observations which are similar to each other, as a function of the time lag between them. A positive autocorrelation (which is usually present in time series of climate data) tends to increase the probability of detecting trends when actually none exist, and vice versa, thus making this test unreliable (Zwiers and Von Storch 1995). Hence the DurbinWatson statistic, a test used to detect the presence of autocorrelation in the residuals obtained from regression analysis was used in the study. The Durbin-Watson test statistic $D$ has the following mathematical equation:

$$
D=\frac{\sum_{t=2}^{n}\left(\epsilon_{t}-\epsilon_{t-1}\right)^{2}}{\sum_{t=1}^{n} \epsilon_{t}^{2}},
$$

where $\epsilon_{t}$ are the residuals from ordinary least squares regression. The hypothesis for the DurbinWatson test is as follows:

$\mathrm{H}_{0}$ : no first-order autocorrelation.

$\mathrm{H}_{1}$ : first-order correlation exists.

If autocorrelation existed in the data, the Hamed and Rao (1998) method at 10\% significant level was taken into account while estimating the trend and trend slope. Hamed and Rao (1998) proposed correcting the variance of the Mann-Kendall test statistic $S$ by using an effective sample size that reflects the effect of serial correlation.

XLSTAT 2016.06.37917 software, an add-in for MS-Excel was used for statistical analysis. The trial version of the software is freely downloadable online. During the trend analysis if ties were detected in the data especially in frequency-related indices, appropriate corrections were applied by the software itself. In this study, a trend was considered to be statistically significant if it was significant at the $10 \%$ level. From the annual and monthwise trendanalysis, $p$-value and Sen's slope were 
calculated for each of the regionally averaged series for all the indices.

\section{Results}

\subsection{Annual trend analysis}

The significance of annual precipitation extreme indices was found to be very low in Central and South Asia from 1961 to 2000. Also regional precipitation extreme indices have not shown any significant trends in Asia (Klein Tank et al. 2006). Previous studies on the trends of rainfall and extreme rainfall events in India have highlighted the following: (i) increased intensity of extreme rainfall especially 1 day rainfall, over the East coast, (ii) increased significance of flood risk over the East coast and (iii) alternating sequence of droughts and flood years in India once in every 30 yr. 1961-1990 were dry periods followed by the beginning of the next sequence of $30 \mathrm{yr}$, (i.e., 19912000) experiencing a wet period (Guhathakurta and Rajeevan 2008; Guhathakurta et al. 2011). Based on the understanding of historical trends of rainfall in India from previous studies, the results of trend analysis for Lower Vellar River sub-basin have been interpreted. The results of annual trend analysis for the study area are given in table 5 .

PRCPTOT has shown a decreasing trend with a slope value of $-17.40 \mathrm{~mm}$ per decade. This

Table 5. Regionally averaged annual trends for rainfall indices at 10\% significance level. p-values and Sen's slope values for the different series are given.

\begin{tabular}{llcc}
\hline & & \multicolumn{2}{c}{ Mann-Kendall trend analysis } \\
\cline { 3 - 4 } Indices & Units & $\begin{array}{c}p \text {-value } \\
(\text { two-tailed) }\end{array}$ & $\begin{array}{c}\text { Sen's } \\
\text { slope }\end{array}$ \\
\hline CDD & days & 0.960 & 0.000 \\
CWD & days & 0.618 & 0.007 \\
R10mm & days & 0.727 & -0.002 \\
R20mm & days & 0.508 & -0.006 \\
R30mm & days & 0.653 & -0.004 \\
RX1day & mm & 0.282 & 0.533 \\
RX3day & mm & 0.861 & 0.155 \\
RX5day & mm & 0.940 & 0.104 \\
SDII & mm/day & 0.960 & -0.001 \\
PRCPTOT & mm & 0.690 & -1.740 \\
R95p & mm & 0.960 & 0.308 \\
R95pT & $\%$ & 0.500 & 0.007 \\
R99p & mm & 0.320 & 1.092 \\
R99pT & $\%$ & 0.252 & 0.013 \\
\hline
\end{tabular}

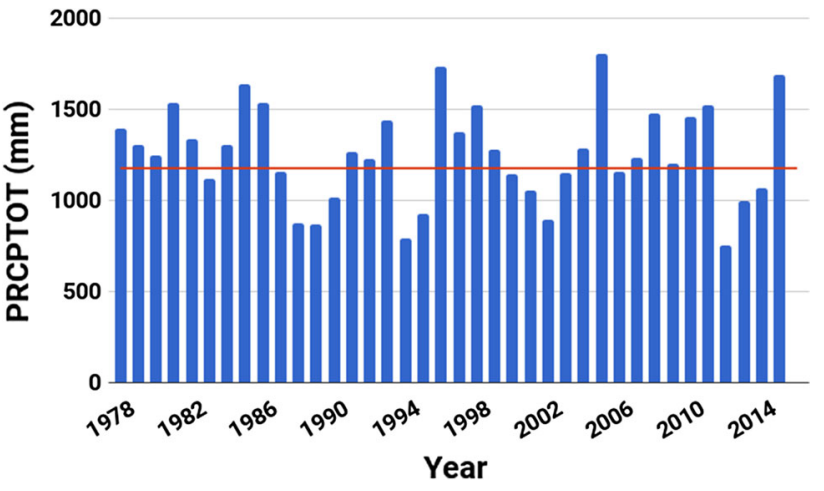

Figure 4. Departures of annual rainfall from the normal in Lower Vellar River sub-basin are represented by the bars. Straight line represents the average annual rainfall of the subbasin of $1176.6 \mathrm{~mm}$. Twenty-three years had surplus rainfall (above normal) and $15 \mathrm{yr}$ had deficit rainfall (below normal).

indicates that the study area is moving towards a drier climate which conforms to the results reported by Guhathakurta and Rajeevan (2008), which show decreasing trends in annual mean rainfall over Tamil Nadu. Figure 4 shows the annual rainfall of the sub-basin plotted with respect to the average annual rainfall of the sub-basin. A total of $23 \mathrm{yr}$ in the duration selected for study had surplus rainfall and 15 yr had deficit rainfall. The years 1981-1982, 1985-1986, 1996-1998, 2005, 2008, 2010, 2011 and 2015 have had the maximum annual rainfall. The above normal rainfall in the aforementioned years can be attributed to cyclonic events in the sub-basin. 2005, 2008, 2010 and 2011 witnessed the impact of cyclones formed as a part of the North Indian Ocean Cyclone Season. 1997, 1982 and 2015 were active El Niño years. The above findings can be validated with the results estimated by Guhathakurta et al. (2011) for India which highlighted the increased flood risk during the years 1971-2000.

SDII showed a decreasing trend with a slope value of $-0.01 \mathrm{~mm} /$ day per decade, which is negligible having no significant effect on the rainfall in the study area. This is similar to the trends of threshold indices R10mm, R20mm and R30mm which also showed a decreasing trend indicating the reduced rainfall intensity. The annual trends have not shown any significance at 10\% level. The duration indices CDD and CWD have shown no trends or insignificant trends with negligible slope values ( $<1$ day). The trends of RX1day, RX3day, RX5day, R95p, R95pT, R99p and R99pT have shown an insignificant positive slope. This is consistent with similar insignificant increasing trends for South Asia (Klein Tank et al. 2006), 
(a) 800

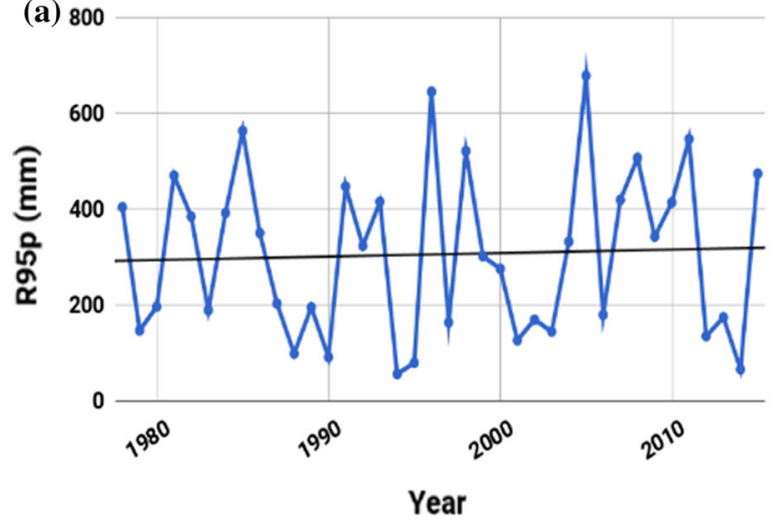

(c) 1.5

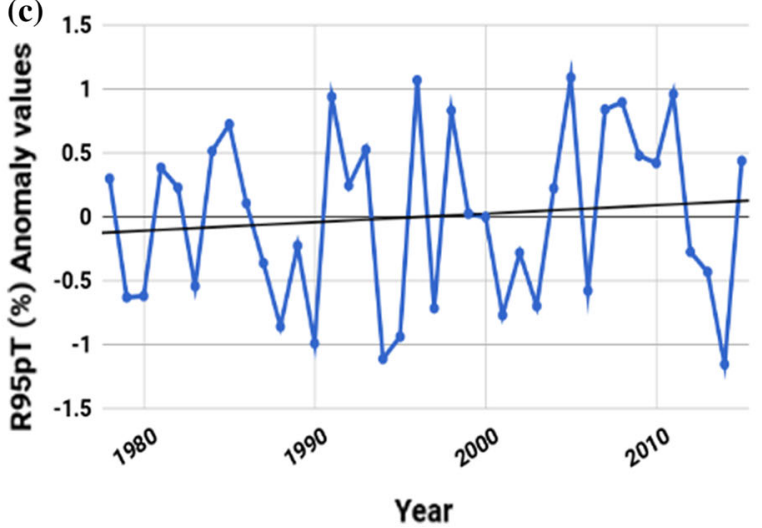



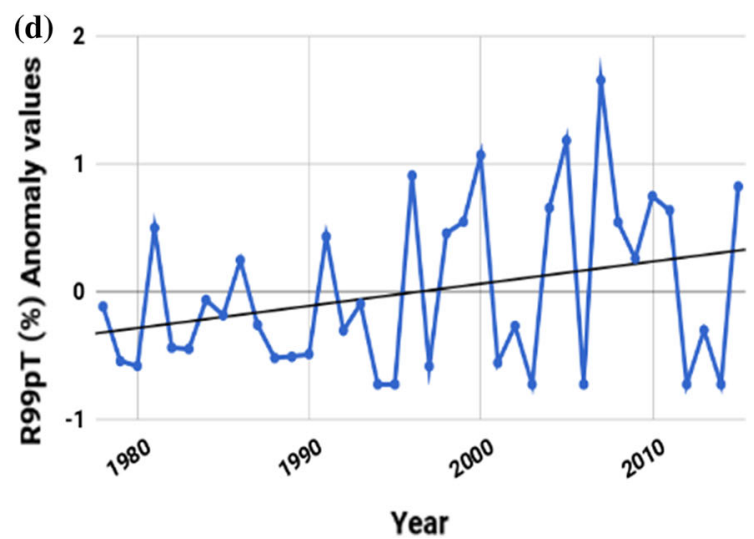

Figure 5. Regionally averaged annual index values of (a) R95p; (b) R99p; (c) R95pT; and (d) R99pT; plotted against time. The straight line represents the linear trend of the indices data.

specifically India (Guhathakurta and Rajeevan 2008; Guhathakurta et al. 2011). Figure 5 shows the positive trends of R95p, R95pT, R99p and $\mathrm{R} 99 \mathrm{pT}$ indices. The trend values imply that there is a slight increase in the amount of rainfall and wet days. The slope per decade for R99p was $10.92 \mathrm{~mm}$ which shows that there is an increase in extremely wet days in a year. This is coherent with the significant increasing trend in $\mathrm{R} 95 \mathrm{p}$ values and insignificant increasing trends of R95pT and R99pT values for the South Asian region between 1961 and 2000 (Klein Tank et al. 2006). This can be further brought down to the months with increased rainfall extremes, from the seasonal trend analysis.

\subsection{Seasonal trend analysis}

The monthly trend values obtained from the analysis were mostly insignificant and the trend slopes have very small slope values. Kumar et al. (2010) have carried out an analysis of long-term trends of rainfall over India, which had also shown very little trend in monsoon rainfall and annual rainfall over
Tamil Nadu between 1875-2005 when compared to the other regions of India. The monthly trend analysis results of regionally averaged indices are given in table 6 , and are used for further seasonal analysis.

\subsubsection{Kharif season}

Kharif season is between June and mid-October. CWD has shown a decreasing trend in the Kharif season with June having a significant decreasing trend. This agrees with PRCPTOT which also shows a decreasing trend though it is insignificant. For the other indices other than CWD and PRCPTOT there has been a consistent increase or decrease in trend corresponding to a particular month. June and July have shown a decreasing trend for nearly all the indices indicating a drier climate. This also implies that not much rain has been received from the SW monsoon. During the month of August comparatively there has been a negligible increase in trends for all indices. September has shown significant negative trends for RX1day, $\mathrm{R} 10 \mathrm{~mm}$ and PRCPTOT which is given in figure 6 . 


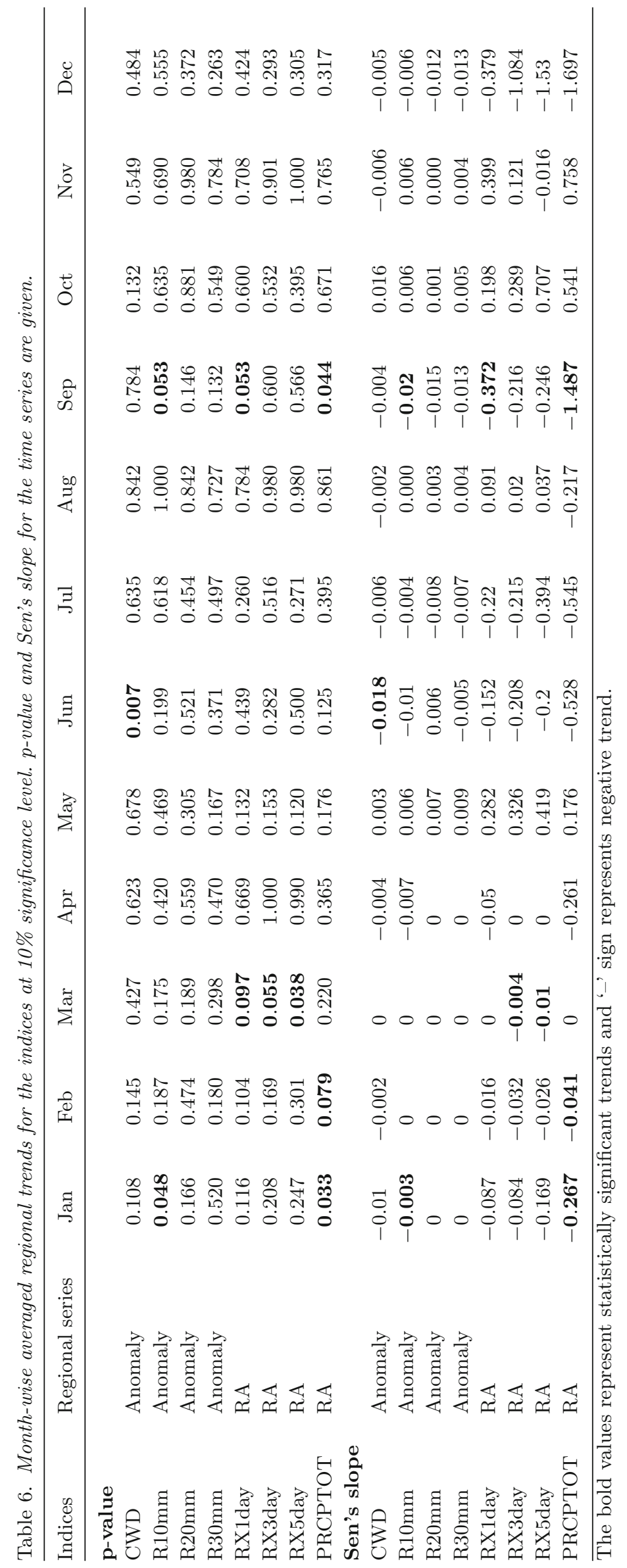



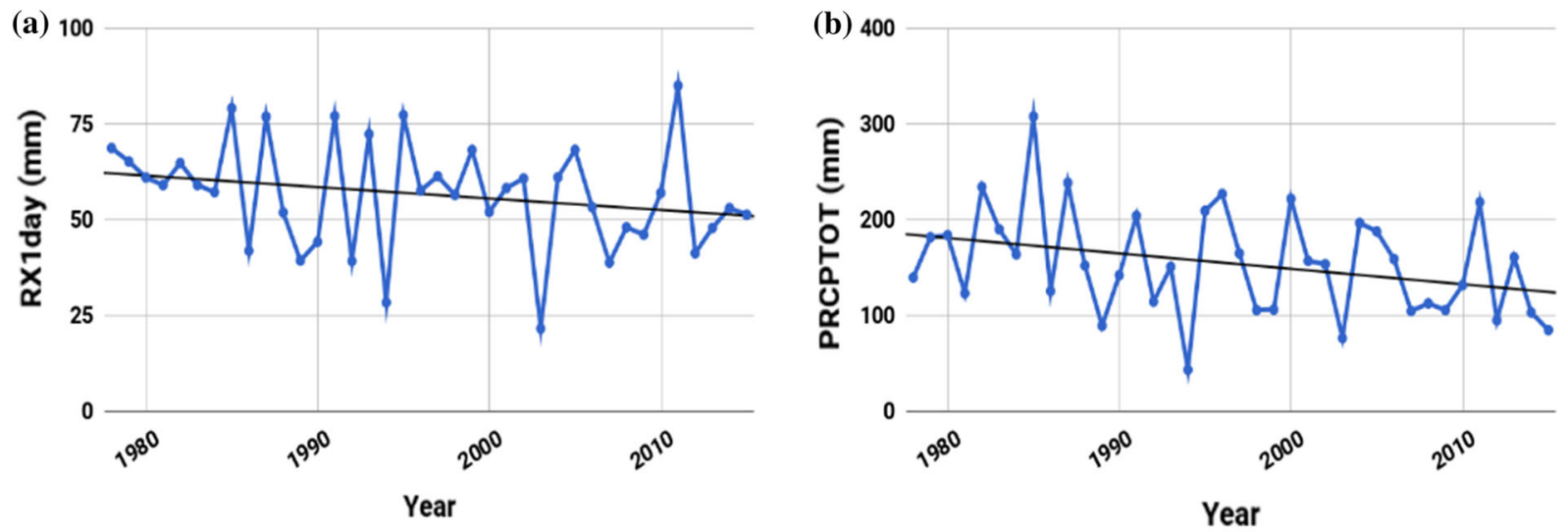

(c)

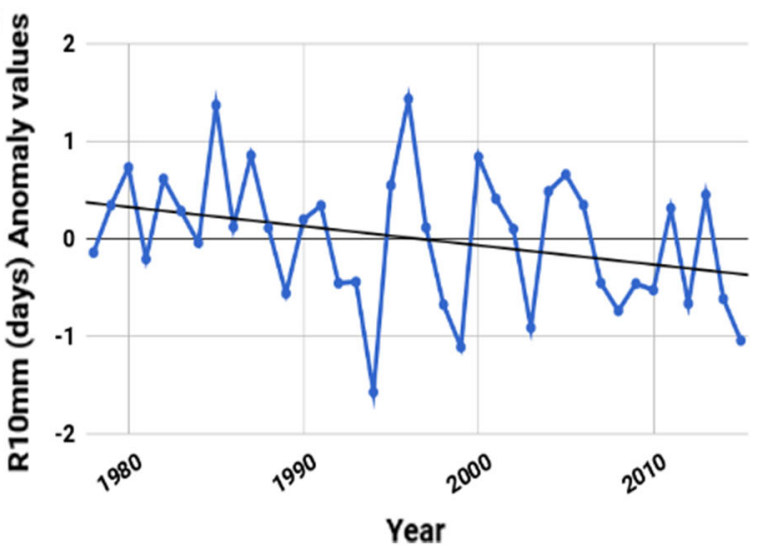

Figure 6. The monthly regional averages for the indices (a) RX1day; (b) PRCPTOT; and (c) R10mm for the month of September which has shown significant trends. The straight line represents linear trend of the indices data.

The values of trend slope per decade were -3.172 and $-14.87 \mathrm{~mm}$ for RX1day and PRCPTOT, respectively. Thus the analysis shows that there is reduced rainfall occurrence during the retreat of monsoon in September. One day maximum rainfall events, one day rainfall intensity and total rainfall from tropical cyclones have considerably reduced since 1978 . Overall the trends show that the Kharif season is moving towards a drier condition.

\subsubsection{Rabi season}

The Rabi season extends from mid-October to May. The onset of the NE monsoon is during October and the analysis has consistently shown an increasing trend for all the indices in October and November, indicating that the months are moving to wetter conditions. From the trend values for monthly maximum 1,3 and 5 days rainfall (RX1day, RX3day, RX5day) trend in October and December, it can be inferred that there has been increased rainfall intensity. The slope values per decade for RX1day during October and November are 1.98 and $3.99 \mathrm{~mm}$, respectively, which indicate that 1 day rainfall intensity has increased over the time period under consideration. This increased rainfall intensity during a specified duration (in this study it is 1,3 or 5 days) can attribute to flash flood events in the sub-basin. December has shown decreased trend values for all indices indicating that the $\mathrm{NE}$ monsoon which gives maximum rainfall during October-December is moving up in the seasonal calendar providing maximum rainfall from late October/November to early December. This is evident from the RX5day rainfall for the month of October which has a slope value of $7.07 \mathrm{~mm}$ per decade which is higher than the RX5day value for the month of November and December which have slope values of $-0.16 \mathrm{~mm}$ per decade and $-15.3 \mathrm{~mm}$ per decade, respectively. The RX3day slope value for December has also shown decreasing trend of $-10.84 \mathrm{~mm}$ per decade. This is evident from Cyclone Thane of 2008 and Cyclone Nisha of 2011 which affected Cuddalore district during November and early December, respectively. The two systems were tropical cyclones over the North 
Indian Ocean which brought heavy rains to the sub-basin during November.

CWD has shown a decreasing or no trend between January and April with an average slope value of -0.04 days per decade. This is in agreement with PRCPTOT which also shows a decreasing trend during the same time period with significant negative trends in January $(-2.67 \mathrm{~mm}$ per decade) and February ( $-0.41 \mathrm{~mm}$ per decade). The absolute and threshold indices have also shown an overall decreasing or no trend between January and April. This shows that the non-monsoon period is fairly dry with not much rainfall events during the period of study.

During March the absolute indices have shown a significant decreasing trend. The RX3day and RX5day indices have slope values of $-0.04 \mathrm{~mm}$ per decade and $-0.1 \mathrm{~mm}$ per decade. The decreasing trend can be related to the decrease in Mango showers which are characteristic to South India. Mango showers are light showers to heavy and persistent thunderstorms formed in the Bay of Bengal. These rains normally occur from March, although their arrival is often difficult to predict. They help in the early ripening of mangoes, a tropical fruit. If this decreasing trend continues it might affect the mango growing belts in the sub-basin.

The month of May is when the summer is at its peak in the study area. The month of May has shown a positive trend for all the indices though they are insignificant. This indicates that there is a slight increase in the occurrence of summer rains also known as pre-monsoon rains or Kodai Mazhai. This rain is advantageous for agriculture as it is the time when farmers prepare their fields for the sowing of Kharif crops. It helps in boosting Kharif sowing in the state. Though there is insignificant increasing trend, it is apparent that the summer rains have remained patchy over Tamil Nadu during the time period 1978-2015.

\subsubsection{Links with El Niño}

Since the NE monsoon rainfall is important for agricultural production in Tamil Nadu (Geethalakshmi et al. 2003), the links between El Niño and the local precipitation need to be studied for guiding the farmers to plan different agricultural activities. Geethalakshmi et al. (2005) investigated the relationship of Southern Oscillation Index (SOI) and Nino-3 sea surface temperature on the NE monsoon rainfall of Tamil Nadu and concluded that the SOI is negatively correlated with the NE monsoon rainfall of Tamil Nadu. This indicates that NE monsoon rainfall of Tamil Nadu is affected by the global climatological signals (Geethalakshmi et al. 2003). Zubair and Ropelewski (2006) have emphasised that the relationship between El NiñoSouthern Oscillation (ENSO) and the NE monsoon rainfall of Tamil Nadu is strengthening.

The effects of El Niño have caused depressions, low-pressure systems and severe cyclones making the NE monsoon very intense in coastal Tamil Nadu. The main consequences of the El Niño years were that the intensity of rainfall was very high and concentrated only for a few days. The rains in Tamil Nadu were excessive in 1997 and 1982, which saw strong El Niño years followed by 2015 which is the strongest El Niño year on record. The 2015 South Indian Floods severely affected Cuddalore district between mid-November and early December. Eleven blocks had been affected by floods and seven blocks had been put under the most affected list. Out of the seven blocks, five blocks - Kurinjipadi, Bhuvanagiri, Keerapalayam, Kattumannarkoil and Kumaratchi fall within the sub-basin under study. On 23 November 2015 the 1 day rainfall in the Cuddalore rain gauge station was $144 \mathrm{~mm}$. The resumption of heavy rainfall from 1 December 2015 again inundated Cuddalore district, causing major crop loss. The highest 1 day rainfall for the month of December was recorded on 2 December 2015 and 3 December 2015 which were 134.8 and $132.8 \mathrm{~mm}$, respectively.

\section{Conclusions}

Though there are not many significant trends in the rainfall indices, the trend slopes obtained from the analysis seem to be factual that there has been an increased occurrence of extreme events such as cyclones in the past 30-40 yr during the month of November and early December. The NE monsoon season has shown a predominantly increasing trend between October and November, and the SW monsoon season has shown a significantly decreasing trend. Regional trend analysis for all indices has shown that there is decreasing or no trend during the non-monsoon season. Values of station-wise PRCPTOT conform to the existing rainfall pattern within the study area. The trends are mostly significant and negative between January and March.

The increasing trends of different rainfall extreme indices during the NE monsoon season which is the main crop growing season in Tamil 
Nadu and the early onset of the NE monsoon over the last few decades are some of the key findings from the study which can be considered as a guiding tool for researchers to develop suitable adaptation strategies for farmers in the Lower Vellar River sub-basin. Adaptation measures can also be developed taking into consideration the occurrence of floods and tropical cyclones in the study area. Since rainfall extremes cause much crop loss both directly and indirectly, the results obtained from the study can help the farmers be wary of such disasters in the future. Water resources planning and development can also be done based on the findings of the study. Water tapped from extreme rainfall events can be used in an efficient manner during the non-monsoon seasons.

Most of the previous studies on rainfall trend analysis have been done for India on an annual/ monthly timescale or for climatic seasons. For the first time, we have developed extreme rainfall indices from the daily rainfall time series for a small region, to calculate the local trends annually and month-wise. The month-wise trends have been analysed for the agricultural cropping seasons of Tamil Nadu to make the data more suitable to help develop adaptation measures.

A systematic analysis of rainfall, rainy days, heavy rainfall spells, etc., on a weekly scale along with radiation, growing degree days, onset and withdrawal dates of monsoon, length of season using onset and withdrawal date, moisture availability and sowing rains, etc., can be done to suggest feasible adaptation strategies. Also, there is scope for developing the extreme climate indices for future modelled data obtained from regional climate models so that it can benefit farmers who are the main stakeholders in agriculture.

\section{Acknowledgements}

We acknowledge Sakthivadivel R, Emeritus Professor, Anna University, Chennai, for his valuable guidance throughout the research period. A special thanks to Arun Babu E for discussions and critical comments. Finally, we thank the anonymous reviewers and the editor for their comments which helped in refining this paper.

\section{References}

Alexander L V, Zhang X, Peterson T C, Caesar J, Gleason B, Klein Tank A M G, Haylock M, Collins D, Trewin B,
Rahimzadeh F, Tagipour A, Rupa Kumar K, Revadekar J, Griffiths G, Vincent L, Stephenson D B, Burn J, Aguilar E, Brunet M, Taylor M, New M, Zhai P, Rusticucci M and Vazquez-Aguirre J L 2006 Global observed changes in daily climate extremes of temperature and precipitation; J. Geophys. Res. Atmos. 111 D05109.

Frei C and Schär C 2001 Detection probability of trends in rare events: Theory and application to heavy precipitations in the Alpine region; J. Clim. 14 1568-1584.

Geethalakshmi V, Balasubramanian T N, Selvaraju R, Bride J M, Huda A K S, Vasanthi C, George D, Clewett J and Thiyagarajan T M 2003 Length of growing period as influenced by El-Nino and La-Nina over Coimbatore, Tamil Nadu, India; J. Agric. Res. Manag. 2(3-4) 31-38.

Geethalakshmi V, Bride J M and Huda A K S 2005 Impact of ENSO on Tamil Nadu rainfall; Vatavaran 29(2) 9-16.

Geethalakshmi V, Yatagai A, Palanisamy K and Umetsu C 2009 Impact of ENSO and the Indian Ocean Dipole on the north-east monsoon rainfall of Tamil Nadu state in India; Hydrol. Process. 23 633-647.

Guhathakurta P and Rajeevan M 2008 Trends in the rainfall pattern over India; Int. J. Climatol. 28 1453-1469.

Guhathakurta P, Sreejith O P and Menon P A 2011 Impact of climate change on extreme rainfall events and flood risk in India; J. Earth Syst. Sci. 120 359-373.

Hamed K H and Rao A R 1998 A modified Mann-Kendall trend test for autocorrelated data; J. Hydrol. 204182 196.

Jones P D and Hulme M 1996 Calculating regional climatic time series for temperature and precipitation: Methods and illustrations; Int. J. Climatol. 16 361-377.

Kendall M G 1955 Rank correlation methods; Hafner Publishing Co., New York.

Kiktev D, Sexton D M H, Alexander L and Folland C K 2003 Comparison of modeled and observed trends in indices of daily climate extremes; J. Clim. 16 3560-3571.

Klein Tank A M G and Können G P 2003 Trends in indices of daily temperature and precipitation extremes in Europe, 1946-1999; J. Clim. 16 3665-3680.

Klein Tank A M G, Peterson T C, Quadir D A, Dorji S, Zou X, Tang H, Santhosh K, Joshi U R, Jaswal A K, Kolli R K, Sikder A B, Deshpande N R, Revadekar J V, Yeleuova K, Vandasheva S, Faleyeva M, Gomboluudev P, Budhathoki K P, Hussain A, Afzaal M, Chandrapala L, Anvar H, Amanmurad D, Asanova V S, Jones P D, New M G and Spektorman T 2006 Changes in daily temperature and precipitation extremes in central and south Asia; J. Geophys. Res. Atmos. 111 D16105.

Kumar V, Jain S K and Singh Y 2010 Analysis of long-term rainfall trends in India; Hydrol. Sci. J. 55 484-496.

Mann H B 1945 Non-parametric tests against trend; Econometrica 13 245-259.

McSweeney C and Caesar J 2013 Additional guidance on quality control and homogeneity testing for the assessment for calculation of extremes indices with RClimDex, based upon guidance notes written for the Met Office Southeast Asian Collaboration; Met Office Hadley Centre, UK.

New M, Hewitson B, Stephenson David B, Tsiga A, Kruger A, Manhique A, Gomez B, Coelho C A S, Masisi D N, Kululanga E, Mbambalala E, Adesina Saleh H, Kanyanga J, Adosi J, Bulane L, Fortunata L, Mdoka M L and Lajoie R 2006 Evidence of trends in daily climate extremes over 
southern and west Africa; J. Geophys. Res. Atmos. 111 D14102.

Palmer T N and Räisänen J 2002 Quantifying the risk of extreme seasonal precipitation events in a changing climate; Nature 415 512-514.

Prasada Rao G S L H V, Rao G G S N and Rao V U M 2010 Climate change and agriculture over India; PHI Learning Private Limited, New Delhi, pp. 1-42.

Sen P K 1968 Estimates of the regression coefficient based on Kendall's tau; J. Am. Stat. Assoc. 63 1379-1389.

Sen Roy S and Balling R C 2004 Trends in extreme daily precipitation indices in India; Int. J. Climatol. $24457-$ 466.

Solomon S, Qin D, Manning M, Chen Z, Marquis M, Averyt K B, Tignor M and Miller H L 2007 Climate change 2007: The physical science basis; Contribution of working group I to the fourth assessment report of the Intergovernmental Panel on Climate Change, Cambridge University Press, Cambridge, UK and New York, NY, USA, pp. 299-316.

Wang X L 2008a Accounting for autocorrelation in detecting mean-shifts in climate data series usingthe penalized maximal $t$ or $F$ test; J. Appl. Meteor. Climatol. $472423-$ 2444.

Wang X L 2008b Penalized maximal F-test for detecting undocumented mean-shifts without trend-change; $J$. Atmos. Ocean Tech. 25 368-384.

Wang X L and Feng Y 2013 RHtests_dlyPrcp user manual, climate research division; Atmospheric Science and Technology Directorate, Science and Technology Branch, Environment Canada, pp. $1-17$.

Wang X L, Chen H, Wu Y, Feng Y and Pu Q 2010 New techniques for detection and adjustment of shifts in daily precipitation data series; J. Appl. Meteor. Climatol. 49 2416-2436.

Zubair L and Ropelewski C F 2006 The strengthening relationship between ENSO and northeast monsoon rainfall over Sri Lanka and southern India; J. Clim. 19 1567-1575.

Zwiers F W and Von Storch H 1995 Taking serial autocorrelation into account in tests of the mean; J. Clim. 8 336-351.

Corresponding editor: A K SAHAI 